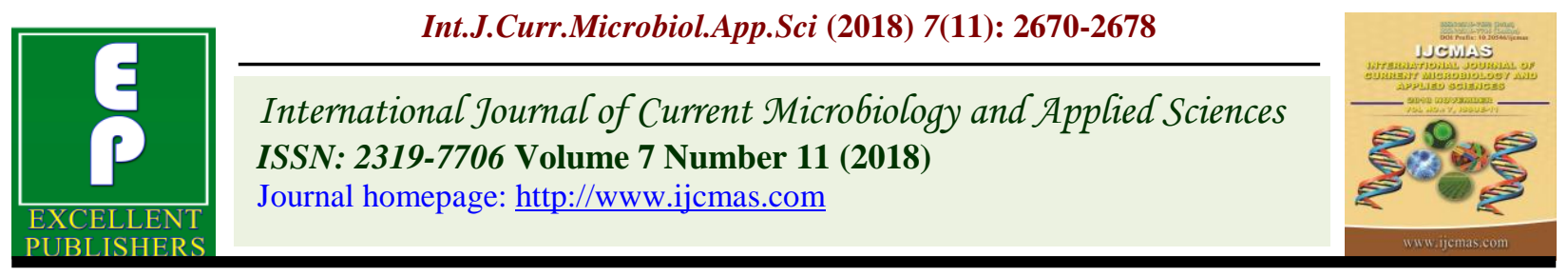

Original Research Article

https://doi.org/10.20546/ijcmas.2018.711.305

\title{
Factors Influencing the Capital Formation of Income and Employment on Krishi Vigyan Kendra in Nagaland
}

\author{
Imsunaro Jamir and Amod Sharma* \\ Department of Agricultural Economics, Nagaland University SASRD Medziphema Campus, \\ District: Dimapur - 797 106, Nagaland, India \\ *Corresponding author
}

\section{A B S T R A C T}

Keywords

KVK, Factors,

Influencing, Capital,

Formation, Income,

Employment

Article Info

Accepted:

22 October 2018

Available Online:

10 November 2018
The present study on impact assessment of Krishi Vigyan Kendra (KVK) training programmes in Nagaland state was undertaken during the year 201213 to 2016-17 (five years) and to assess the impact of income as well as employment generated it was categorized into two groups viz; adopted and non-adopted villages ( 80 respondents to each category). To achieve the objectives of the present study a multi stage purpose random sampling methods was adopted. Further the study also highlighting the different influencing factors, which are enhancing the income and employment of selected KVK's in the state of Nagaland.

\section{Introduction}

The state is predominantly rural with 82.26 per cent of population living in villages. The state comprises of 11 administrative headquarters with 52 blocks and 1,278 inhabited villages. Each district has generally predominance / concentration of one of the major / minor tribe of the state, thereby making the districts distinct in their linguistic, cultural, traditional and socio-political characteristics. The topography of Nagaland is much dissected, full of hill ranges which break into a wide chaos of spurs and ridges. The terrain is mountainous covered by rich and varied biodiversity of flora and fauna. It is one of the 25 hotspots of the world with respect to its biological diversity, and hence can be termed as the state of true Mega bio-diversity. The state houses the confluence of flora and fauna of the neighbouring regions.

Geographically, the state largely has vast undulating terrain and hilly landscape and some low lying areas giving rise to a very conducive climate with presence of perennial water and moisture for truly rich variety of flora and fauna. The state also has abundant resources of mineral wealth in the form of vast deposits of Oil, Coal, Peat, Limestone, Iron ores and various other minerals. The potential of this state in terms of the sheer variety of Agro and Horticultural produce including Fiber, Tea, Coffee, Pineapple, Orange etc. is 
also immense. In spite of this inherent potential, the state has not developed. The current practice of agriculture is largely unsustainable owing to the traditional Jhum (Shifting cultivation) cycle mode of operation. Though some dynamic initiatives (e. g; by various government, Department, NGO's etc.) are in action to mitigate the detrimental effects of Jhum, a lot still needs to be done on various fronts including efforts on checking deforestation, control of wild fire, conservation of biodiversity, proper water harvesting, use of non-conventional energy sources etc. The state also lacks infrastructure development in terms of networking with the rest of the country, lack of proper communication in terms of roads and information technology.

Krishi Vigyan Kendras (Farm Science Centre), an innovative science based institutions, are the only district - level institutions with a proven potentiality to build farmers' capacity on their multi-dimensional requirements in a scientific and systematic approach which is established mainly to impart vocational training to the farmers and field level extension workers. The concept of vocational training in agriculture through KVK grew substantially due to greater demand for improved agricultural technology by the farmers. They not only required knowledge and understanding of the intricacy of technologies, but also progressively more and more skills in various complex agricultural operations for adoption on their farms.

The effectiveness of the KVK was further enhanced by adding the activities related to on-farm testing and Front-Line Demonstration on major agricultural technologies in order to make the training of farmers location specific, need based and resource-oriented. The training programmes were designed to impart the latest knowledge to the farmers through work experience by applying the principles of 'Teaching by Doing' and 'Learning by Doing'. The prime goal of KVK is to impart training as per needs and requirements in agriculture and allied enterprises to all farmers, farm women and farm youths including school drop-outs in the rural area. While designing the courses, the concept of farming system as well as farming situation are taken into account to ensure that the enterprises in which they are trained are commercially and ecologically viable, sustainable and profitable. Such vocational trainings help them to sustain themselves through self-employment and to make them self-reliant economically and thus discourages them to migrate to the urban areas. KVKs provide training not only in agriculture and allied vocations but also in other incomegenerating activities that may supplement the income of farm families. The methods employed in training could be formal and nonformal or a combination of both, depending upon the needs but emphasis remains to be on work-experience. The programmes of each KVK cover training, on-farm trials, frontline demonstrations, agricultural extension and livelihood activities. Keeping in view the above fact, the present study was undertaken, with the two objectives viz; to study the present status and activities of KVK's and factors influencing the income and employment of KVK's.

\section{Materials and Methods}

The present study is to assess the impact of KVK for disseminating the agriculture technology to the farming community in Nagaland state, which is working as per the guidelines of Central Government with the help of Ministry of Agriculture, Government of India. The sampling design and analytical techniques to be used in the light of objectives laid down for the study have been presented under the following sub-headings. 


\section{Locale of the study}

The develop projects require long period of time to reap the benefit, therefore for economic appraisal of development, it is essential that the scheme has been in operation for quite some time. Since the intensive KVK started in 1988-89, so it is worth -while to study its impact. Since the data of the initial period cannot be compared with the data of recent years, it is more scientific and practical to compare the economy of the beneficiaries / trainees covered in the area of KVK schemes.

\section{Selection of districts}

The KVK was launched in 1988-89 in all 11 districts viz; Dimapur, Kohima, Kiphire, Longleng, Mokokchung, Mon, Phek, Peren, Tuensang, Wokha and Zunheboto of Nagaland, out of these districts two district viz; Mokokchung and Zunheboto districts of Nagaland have been selected because of the fact that it is expected to provide all the relevant information and hence can conveniently be obtained for conducting this study. The project area also has a good network of infrastructure and allied activities related to the scheme such as development agencies, nationalized banks, well-established marketing and communication facilities etc. Keeping all the above facts, both districts of Nagaland are therefore purposively selected to conduct this study.

\section{Selection of Blocks}

Two blocks from each district will be selected randomly for the present study as these blocks are well covered by KVK programmes.

\section{Selection of villages}

Altogether eight villages were selected randomly from each district, while four villages from each block were selected and listed which would be obtained from the offices of SDO (Civil), R. D. block headquarter and other related offices. However, it is proposed to select four villages from each block randomly covered for $\mathrm{KVK}$ programme / schemes.

\section{Selection of Farmers}

After selection of the villages, a list of beneficiaries and non-beneficiaries of $\mathrm{KVK}$ will be prepared from each of the selected village. In order to have representative sample from each village a sample of 20 numbers of cases of KVK, out of that 10 from beneficiaries and 10 from non-beneficiaries will be drawn following the purposively random sampling method. This will result in selection of 160 respondents from 8 villages, out of which 80 will be beneficiaries of KVK schemes and 80 will be non-beneficiaries of KVK schemes.

\section{Data Collection}

The study will be based on primary and secondary data. Secondary data will be collected from secondary sources viz; office of the Zonal Project Director Office, Krishi Vigyan Kendra (KVK), KVK Centre at Mokokchung and Zunheboto districts, various published materials from the Directorate of Agriculture, Directorate of Horticulture, Directorate of Animal Husbandry and Veterinary, Government of Nagaland, etc. In order to identify the constraints in implementing the KVK programmes, discussion with KVK functionaries at district level / block level etc. will be conducted. Besides, data on demographic features, land use pattern, livestock population, climate, rainfall, area under irrigation, institutional infrastructure etc.; will also be collected from various statistical abstracts of the districts and state which will enlighten the socio-economic and infrastructural scenario of the area under 
study. The primary data will be collected through pre-tested and pre-structured schedules and questionnaires especially designed for this study.

\section{Analytical techniques and tools}

Collected data will be scrutinized, tabulated and processed systematically according to the objectives laid down for the study. Tabular and functional analysis will be used to meet the objectives of the study as and where needed, data were analysed by tabular presentation method where frequencies and percentages were used, mean, standard deviations were used to categorise the sample. Impact index was used to find the extent of KVK's training / programme for adopted and non-adopted both groups. Frequency and percentage were used for tabular analysis. Mean and standard deviation were computed to categorize the respondents. Paired ' $t$ ' test was used to know the significance of difference in Impact assessment before and after taking income generating activity. The chi-square analysis was used to find the association between different activities and socio-economic characteristics of respondents. Modified chi-square values were calculated for the data where cell frequencies were less than five.

\section{Annual income}

The annual income of the respondent was worked by taking into account income from income generating activities of adopted and non-adopted KVK's programme and other subsidiary occupations per year. Categorization of annual income was done as follows:

Classification of Income Category Annual income (Rs)

Low income Less than (mean - 0.425 SD),
Medium income Between (mean $\pm 0.425 \mathrm{SD}$ ), and

High income More than (mean $+0.425 \mathrm{SD})$.

\section{Employment generation}

Employment generation includes all the persons employed in a venture on a temporary or permanent basis. It does include the owner entrepreneur himself / herself. This variable was measured by considering the number of mandays of work generated. The mandays were calculated by following the procedure of one manday or women day is equal to eight hours of work and by considering the criteria based on over all mean employment generation so all the respondents were grouped into three categories viz;

Low (mean - 0.425 SD),

Medium (mean $\pm 0.425 \mathrm{SD}$ ), and

High (mean + 0.425 SD).

\section{Results and Discussion}

The present study was based on the selected KVK's adopted and non-adopted farmers. The data were analysed as per the requirement of the stated objectives.

Table 1 reveals the overall change in human capital due to enhancement of income / employment generation (in percentage). Data clearly indicates overall increase from low to medium and medium to high category of human capital. Before it was 31 (38.75 per cent) that lowered down to 23 (28.75 per cent), which is an indication of positive sign. Further on medium group, before it was 35 (43.75 per cent) which remain the same after also. There has been an increase from low group to medium group and from medium to high group, while on high group, before it was 14 (17.50 per cent) which has increased to 22 (27.50 per cent). Overall percentage has also 
shifted due to the increase in human capital of 36.98 per cent due to the income / employment based training / programme organised by the KVK's, respectively.

Table 2 reveals the overall change in Physical capital due to enhancement of income / employment generation (in percentage). Data clearly indicates overall increase from low to medium and medium to high category of Physical capital. Before it was 42 (52.50 per cent) which lowered down to 31 (38.75 per cent), indicating positive sign. Further on medium group, before it was 30 (37.50 per cent) and after it become 37 (46.86 per cent). There has been a shift from low group to medium group and from medium to high. While on high group, before it was 8 (10.00 per cent) and after it was12 (15.00 per cent). Overall percentage of physical capital shows increase of 33.54 per cent due to the income / employment based training / programme conducted by the KVK's, respectively.

Table 3 reveals the overall change in Social capital due to enhancement of income / employment generation (in percentage). Data clearly indicates overall increase from low to medium and medium to high category of Social capital. Before it was 28 (35.00 per cent) which lowered down to 16 (20.00 per cent) indicating a positive sign. Further on medium group, before it was 36 (45.00 per cent) and after it become 43 (56.25 per cent). There has been a shift from low group to medium group and then from medium to high group also. While on high group, before it was 16 (20.00 per cent) and after it was 21 (26.25 per cent). The overall percentage of social capital shows increase of 34.17 per cent due to the income / employment based training / programme organised by the KVK's, respectively.

Table 4 reveals the overall change in Financial capital due to enhancement of income / employment generation (in percentage). Data clearly indicates overall increase from low to medium and medium to high category of Financial capital. Before it was 25 (31.25 per cent) which lowered down to 18 (22.50 per cent) indicating a positive sign. Further on medium group, before it was 39 (48.75 per cent) and after it become 41 (60.94 per cent). There has been a shift from low group to medium group and then from medium to high group also. While on high group, before it was 16 (20.00 per cent) and after it was 21 (26.25 per cent). The overall percentage of financial capital shows increase of 36.56 per cent due to the income / employment based training / programme organised by the KVK's, respectively.

Table 5 reveals the overall change in Food Security due to enhancement of income / employment generation (in percentage). Data clearly indicates overall increase from low to medium and medium to high category of Food Security. Before it was 14 (17.50 per cent) which lowered down to 12 (15.00 per cent) indicating a positive sign. Further on medium group, before it was 54 (67.50 per cent) and after it become 46 ( 84.38 per cent). There has been a shift from low group to medium group and then from medium to high group also, while on high group before it was $12(15.00$ per cent) and after it was 22 (27.50 per cent). The overall percentage of food security shows increase of 42.29 per cent due to the income / employment based training / programme organised by the KVK's, respectively.

Table 6 reveals the overall change in Overall Capital Worth due to enhancement of income / employment generation (in percentage).

Data clearly indicates overall increase from low to medium and medium to high category of Overall Capital Worth. Before it was 28 (35.00 per cent) which lowered down to 20 (25.00 per cent) indicating a positive sign. 
Table.1 Change in human capital due to income / employment generation

\begin{tabular}{|c|c|c|c|c|c|}
\hline \multirow[t]{2}{*}{ S. N. } & \multirow[t]{2}{*}{ Category } & \multicolumn{2}{|c|}{ Before } & \multicolumn{2}{|c|}{ After } \\
\hline & & Frequency & Per cent & Frequency & Per cent \\
\hline 1. & Low & 31 & 38.75 & 23 & 28.75 \\
\hline 2. & Medium & 35 & 43.75 & 35 & 54.68 \\
\hline 3. & High & 14 & 17.50 & 22 & 27.50 \\
\hline \multicolumn{2}{|c|}{ Overall / Average } & 80 & 100.00 & 80 & 36.98 \\
\hline & Mean & \multicolumn{2}{|c|}{15.28} & \multicolumn{2}{|c|}{21.24} \\
\hline & SD & \multicolumn{2}{|c|}{3.21} & \multicolumn{2}{|c|}{4.72} \\
\hline
\end{tabular}

Table.2 Change in physical capital due to income / human generation

\begin{tabular}{|c|l|c|c|c|c|}
\hline \multirow{2}{*}{ S. N. } & \multirow{2}{*}{ Category } & \multicolumn{2}{|c|}{ Before } & \multicolumn{2}{c|}{ After } \\
\hline & & Frequency & Per cent & Frequency & Per cent \\
\hline 1. & Low & 42 & 52.50 & 31 & 38.75 \\
\hline $\mathbf{2 .}$ & Medium & 30 & 37.50 & 37 & 46.86 \\
\hline $\mathbf{3 .}$ & High & 8 & 10.00 & 12 & 15.00 \\
\hline Overall / Average & 80 & & 100.00 & 80 & 33.54 \\
\hline Mean & \multicolumn{3}{|c|}{5.56} & & 8.98 \\
\hline
\end{tabular}

Table.3 Change in social capital due to income / human generation

\begin{tabular}{|c|c|c|c|c|c|}
\hline \multirow[t]{2}{*}{ S. N. } & \multirow[t]{2}{*}{ Category } & \multicolumn{2}{|c|}{ Before } & \multicolumn{2}{|c|}{ After } \\
\hline & & Frequency & Per cent & Frequency & Per cent \\
\hline 1. & Low & 28 & 35.00 & 16 & 20.00 \\
\hline 2. & Medium & 36 & 45.00 & 43 & 56.25 \\
\hline 3. & High & 16 & 20.00 & 21 & 26.25 \\
\hline \multicolumn{2}{|c|}{ Overall / Average } & 80 & 100.00 & 80 & 34.17 \\
\hline \multicolumn{2}{|r|}{ Mean } & \multicolumn{2}{|c|}{12.67} & \multicolumn{2}{|c|}{19.24} \\
\hline \multicolumn{2}{|r|}{ SD } & \multicolumn{2}{|c|}{3.02} & \multicolumn{2}{|c|}{2.92} \\
\hline
\end{tabular}

Table.4 Change in financial capital due to income / human generation

\begin{tabular}{|c|l|c|c|c|c|}
\hline \multirow{2}{*}{ S. N. } & \multicolumn{2}{|c|}{ Category } & \multicolumn{2}{|c|}{ Before } & \multicolumn{2}{c|}{ After } \\
\cline { 3 - 7 } & & Frequency & Per cent & Frequency & Per cent \\
\hline 1. & Low & 25 & 31.25 & 18 & 22.50 \\
\hline 2. & Medium & 39 & 48.75 & 41 & 60.94 \\
\hline 3. & High & 16 & 20.00 & 21 & 26.25 \\
\hline Overall / Average & 80 & & 100.00 & 80 & 36.56 \\
\hline Mean & & 5.76 & & & 7.65 \\
\hline
\end{tabular}


Table.5 Change in food security due to income / human generation

\begin{tabular}{|c|c|c|c|c|c|}
\hline \multirow[t]{2}{*}{ S. N. } & \multirow[t]{2}{*}{ Category } & \multicolumn{2}{|c|}{ Before } & \multicolumn{2}{|c|}{ After } \\
\hline & & Frequency & Per cent & Frequency & Per cent \\
\hline 1. & Low & 14 & 17.50 & 12 & 15.00 \\
\hline 2. & Medium & 54 & 67.50 & 46 & 84.38 \\
\hline 3. & High & 12 & 15.00 & 22 & 27.50 \\
\hline \multicolumn{2}{|c|}{ Overall / Average } & 80 & 100.00 & 80 & 42.29 \\
\hline & Mean & \multicolumn{2}{|c|}{7.76} & \multicolumn{2}{|c|}{10.87} \\
\hline & SD & \multicolumn{2}{|c|}{1.86} & \multicolumn{2}{|c|}{1.01} \\
\hline
\end{tabular}

Table.6 Change in overall capital worth due to income / human generation

\begin{tabular}{|c|l|c|c|c|c|}
\hline \multirow{2}{*}{ S. N. } & \multirow{2}{*}{ Category } & \multicolumn{3}{|c|}{ Before } & \multicolumn{2}{c|}{ After } \\
\hline & & Frequency & Per cent & Frequency & Per cent \\
\hline 1. & Low & 28 & 20 & 35.00 & 25.00 \\
\hline 2. & Medium & 39 & 40 & 48.75 & 60.94 \\
\hline 3. & High & 13 & 20 & 16.25 & 25.00 \\
\hline Overall / Average & 80 & 80 & 100.00 & 36.98 \\
\hline Mean & & 43.76 & \multicolumn{2}{|c|}{63.72} \\
\hline
\end{tabular}

Table.7 Overall capital formation factors for increased in income \& employment (\%)

\begin{tabular}{|c|l|c|c|c|}
\hline S. N. & \multicolumn{1}{|c|}{ Particulars } & Before & After & 't' value \\
\hline 1. & Human Capital (HC) & 47.50 & 71.25 & $11.52^{* *}$ \\
\hline 2. & Physical Capital (PC) & 48.75 & 62.50 & $10.79 * *$ \\
\hline 3. & Social Capital (SC) & 46.25 & 74.25 & $14.58^{* *}$ \\
\hline 4. & Financial Capital (FC) & 41.25 & 68.75 & $12.38^{* *}$ \\
\hline 5. & Food Security (FS) & 53.75 & 64.87 & $7.18^{*}$ \\
\hline 6. & Overall Capital (OC) & 51.82 & 69.00 & $12.05^{* *}$ \\
\hline
\end{tabular}

(** \& * Significant at $1 / 5$ per cent level of significance)

Further on medium group, before it was 39 (48.75 per cent) and after it become 40 (60.94 per cent) which shows a shift from low group to medium group and then from medium to high group. While on high group, before it was 13 (16.25 per cent) and after it was 20 (25.00 per cent). The percentage of overall capital worth shows increase of 36.98 per cent due to the income / employment based training / programme organised by the KVK's, respectively.
Table 7 reveals the change in Overall formation factors for the enhancement of income and employment generation (in percentage). Data clearly indicates an increase from Overall Capital Worth. Before it was 51.82 per cent and after getting programme / training, it has increased up to 69.00 per cent, which was also found to be significant at 1 per cent level of significance of paired ' $t$ ' test indicating positive sign for the impact of income / employment based training / 
programme conducted by the KVK's in the study area. On the Human Capital (HC) aspect, before it was 47.50 per cent and after getting programme / training it has increased up to 71.25 per cent, which was found to be significant at 1 per cent level of significance, also on Physical Capital (PC) aspect, before it was 48.75 per cent and after getting programme / training, it has increased up to 62.50 per cent, which was found to be significant at 1 per cent level of significance.

Further on Social Capital (SC) aspect, before it was 46.25 per cent and after getting programme / training it has increase up to 74.25 per cent, which was found to be significant at 1 per cent level of significance. On Financial Capital (FC) aspect, before it was 41.25 per cent and after getting programme / training it has increased up to 68.75 per cent, which was found to be significant at 1 per cent level of significance. On Food Security (FS) aspect, before it was 53.75 per cent and after getting programme / training it has increase up to 64.87 per cent, which was found to be significant at 5 per cent level of significance indicating a positive sign for the impact of income / employment of KVk's, respectively.

The study was undertaken in two blocks each of Mokokchung and Zunheboto districts, which were selected keeping all the specific objectives to be fulfilled. A purposive stratified random sampling method was adopted and for the assessment of impact of income and employment of the KVK's training / programme in the study area, parameters were selected.

For the study, sample farmers size was selected from eight villages from four blocks of both district. The overall objective of the study was to make comprehensive analysis of the impact of different schemes or programme.
Certainly there are many factors which were left out to be considered as a factor to achieve the objectives in a better way, out of that few had been listed below:

The present study was conducted in the selected two blocks of the Mokokchung and Zunheboto districts; so conclusion cannot be drawn in general for other (remaining) districts of the state due to the variation of implementation and selected scheme which were implemented by the KVK's based on the priority and need of the areas as well as trained manpower available.

Even the present study was based from 201213 to 2016-17 which may not include the different factors governing for the increasing the income and employment.

The different problems highlighted may be considered as it was the opinion of the respondents in the study areas.

Few suggestions highlighted must be given priority in the days to come for the betterment of the rural farmers.

The present study may be used as bases of the future study and in depth study may be encouraged to find out the other factors not covered so far.

\section{References}

Analogous. 2017. Statistical Hand of Nagaland Published by Directorate of Economics and Statistics (various issues), Kohima, Nagaland.

Pongener, Bendangjungla. and Sharma, Amod. 2018. Constraints Faced by the Fishery Enterprises: A SWOC Analysis. IJCMAS. 7(5). May: 1595-1603.

Sangtam, Likhase. L. T. and Sharma, Amod. 2015. Impact of Bank Finance on Employment and Income through 
Piggery Enterprise in Nagaland. EPRAIJEBR. 3(11). Nov: 273-276.

Sharma, A. 2002. Source and Knowledge on beneficiaries about the purpose of credit - A case study of Agra Region of Uttar Pradesh. Journal of Interacademica. 6(3). July: 374-379.

Sharma, A. 2004. Constraints of Fish Production - A case study in rainfed areas of Uttar Pradesh. Journal of Interacademica. 8(4). October: 639643.

Sharma, A. and Sharma, Anamika. 2008. Problems faced by the farmers in adoption of improved maize cultivation practices in hills. TJRAR. 8(2): 22-23.

Sharma, Amod. 2011. Economic and Constraints of King Chilli Growers in Dimapur District of Nagaland. Journal of Interacademicia. 15(4): 710-719.

Sharma, Amod. 2012. Inter-state Disparities in Socio-economic Development in North East Region of India. Journal of Agricultural Science. 4(9). September: 236-243.

Sharma, Amod. 2014. Sustainable economic analysis and extent of satisfaction level of King Chilli growers in Nagaland. Agriculture for Sustainable Development. 2(1). June: 188-191.

Sharma, Amod.; Kichu, Yimkumba. and Chaturvedi, B. K. 2016. Economics and Constraints of Pineapple Cultivation in Dimapur District of Nagaland. TJRAR. 16(1). January: 72-75.
Sharma, Amod.; Kichu, Yimkumba. and Sharma, Pradeep. Kumar. 2018. Sustainable economic analysis and constraints faced by the pineapple growers in Nagaland. Progressive Agriculture. 18(1). February: 27-33.

Shuya, Keviu. and Sharma, Amod. 2014. Impact and constraints faced by the borrowers of cooperative bank finance in Nagaland. Economic Affairs. 59(4). October: 561-567.

Shuya, Keviu. and Sharma, Amod. 2018. Problems faced by the Borrowers in Utilization and Acquiring of Cooperative Bank Loans in Nagaland. IJED. 14(2). April-June: 52-56.

Tangjang, Avicha. and Sharma, Amod. 2018. Problem faced by the Large Cardamom Growers during production and marketing: A case study of Tirap district of Arunachal Pradesh. IJCMAS. 7(5). May: 2561-2573.

Walling, Imti. and Sharma, Amod. 2015. Impact of SGRY on beneficiaries and non-beneficiaries in Dimapur district of Nagaland. TJRAR. 15(2). August: 9094.

Walling, Imti.; Sharma, Amod.; Yadav, Mukesh. Kumar.; Rajbhar, Arun, Kumar. and Kalai, Kankabati. 2017. Impact of Agricultural Technology Management Agency on Rural Economy of Nagaland, India. Plant Archiver. 17(2). October: 1511-1516.

\section{How to cite this article:}

Imsunaro Jamir and Amod Sharma. 2018. Factors Influencing the Capital Formation of Income and Employment on Krishi Vigyan Kendra in Nagaland. Int.J.Curr.Microbiol.App.Sci. 7(11): 2670-2678. doi: https://doi.org/10.20546/ijcmas.2018.711.305 